\title{
LINAEDULATION
}

02-04 JULY, 2021

Oxford, United Kingdom

\section{Application of Unified Theory of Acceptance and Use of Technology to Learning Management System Use: A Study of Ahmadu Bello University Distance Learning Centre}

\author{
Fatima Shehu Kabir ${ }^{1}$, Ibrahim Shehu ${ }^{2}$ \\ ${ }^{1}$ Department of Science Education Faculty of Education Kaduna State University \\ ${ }^{2}$ Department of Public Administration Faculty of Administratio Ahmadu Bello University, Zaria.
}

\begin{abstract}
The study examined the application of Unified Theory of Acceptance and Use of Technology (UTAUT) to Learning Management System (LMS) in Ahmadu Bello University Distance Learning Centre using a sample of 149 E-tutors. The study utilized primary data collected using the instrument of questionnaire and analyzed using multiple linear regression. Findings of the study revealed that performance expectancy and facilitating condition have positive influence on behavioural intention to use LMS in Ahmadu Bello University Distance Learning Centre. However, the study found that effort expectancy and social influence have negative influence on behavioural intention to use LMS in Ahmadu Bello University Distance Learning Centre. The study recommends that the management of ABUDLC should provide E-tutors with more facilitating conditions particularly, technical support and regular training on LMS use.
\end{abstract}

Key words: Ahmadu Bello University, Distance Learning, Unified Theory of Acceptance and Use of Technology, Learning Management System.

\section{INTRODUCTION}

Face-to-face education in today's world has gradually given way, using digital technologies, into the virtual space. Additionally, in today's fast-moving world, many traditional teaching methods are inefficient and lack the power to transfer new knowledge and concepts to learners. Indeed, educational delivery in this decade is dominated by use of Information and Communication Technologies (ICT). According to Anene \& Oduma (2015) in spite the various challenges posed by the use of emerging technologies in teaching and learning in Nigeria, there is increasing awareness on the use of such Information and Communication Technologies (ICTs) in teaching and learning. Distance Education and online instruction are forms of today's Technology Enhanced Learning 


\section{LICNAEDULATIIN}

02-04 JULY, 2021

Oxford, United Kingdom

systems, which have become viable tools necessary for preparing todays learners to participate in the technologically driven global environment. International research has shown that students now spend much of their time on internet, engaged in one or another online learning platforms, and exchanging information via social networks (Johnson et al, 2013). This corroborates the theory of "Digital Natives and Digital Immigrants" propounded by Prensky (2001) in Kabir (2017). The digital generation of students are demanding a transformation in their classrooms because of their ability to access information faster than any other generation using digital affordances. These resources available today for use in the classrooms would include overhead projector, LCD projector, internetenabled access devices like smart electronic boards, laptops, tablets and many others.

Learning Management System (LMS) also called Virtual Learning Environment, is an enhanced form of classroom teaching, which provides a virtual environment for learning interactions to take place. This, and many other new technologies such as Open Educational Resources (OERs), Massive Open Online Courses (MOOCs), have transformed education to be more global where students learn with the help of the Internet. These Virtual Learning Environments (VLEs) provide tools to deliver instructor-led synchronous and asynchronous online training. They also provide tools for authoring content as well as providing virtual spaces for learner interaction (such as discussion forums and live chat rooms). Many institutions use these VLEs as their platform to conduct fully online courses (Nicholas-Omoregbe, 2017). Indeed Sife et al (2007) stated that both trainers and learners can choose more appropriate technology applications which are flexible in time, in place, personalized, reusable, adapted to specific domains and more cost-efficient. Against this background, the study tends to examine the relationship between Unified Theory of Acceptance and Use of Technology (UTAUT) and Learning Management System in the Distance Learning Centre, Ahmadu Bello University, Zaria.

\section{LITERATURE REVIEW AND THEORETICAL FRAMEWORK}

\subsection{Literature Review}

Extensive work has been done on the use of Unified Theory of Acceptance and Use of Technology (UTAUT) to determine the association between constructs and the behavioural Intention and use of information technology. However, studies that applied the UTAUT construct to LMSs in Nigeria is quite sparse. A number of previous studies have focussed on examining the volume of LMS usage, features used within an LMS, and attitudes towards using such systems. Adedoja et al (2013) research was based on Davis's Technology Acceptance Model and tested multiple hypotheses concerning the effects of Perceived Usefulness, Perceived Ease of Use, Interest in the Technology and Technology Self-efficacy on the use of the mobile tutorials. Shittu et al (2013) conducted a study to understand students' attitudes and behavioural intention towards the adoption of the Internet for learning. Kabir (2018) investigated the relationship between awareness and usage of mobile devices among facilitators and students in distance education in tertiary institutions in Nigeria and concluded that there was no positive relationship between the two variables

Many similar studies have been carried out outside Nigeria, and they include: The survey by Claar, Dias \& Shields (2014), which measured several technology acceptance factors based on the 
technology acceptance model (TAM). The results supported relationships between the variables: Perceived Ease of Use (PE), perceived usefulness (PU); and Attitude toward using (AT). Lin, Lu \& Liu (2013) reviewed and assessed models of behavioral intention which includes TAM, TAM2, TPB and UTAUT. This research generated a new conceptual model (the Education Behavioral Intention Model (EduBIM)) to explain the effect of teaching styles and learning styles on the extent of acceptance of e-learning systems. The proposed research model incorporates the above-mentioned constructs to understand system adoption more comprehensively and assesses e-learning management systems in higher education. The research by Alrawashdeh, Muhairat and Alqatawnah (2012) extended Unified Theory of Acceptance and Use Technology (UTAUT) using some factors involving flexibility of web. In a different study, Asiri, Mahmud, Abu-Bakar, and Ayub (2012) studied faculty members' utilisation of JUSUR LMS at three public universities in Saudi Arabia and their attitude towards such utilisation in (Al Harbi, 2014). Maina and Nzuki (2015) sought to adopt the Unified Theory of Acceptance and Use of Technology (UTAUT) to explore or study factors influencing student's E-learning Management System (ELMS) adoption in Institutions of higher education.

Other empirical studies were reviewed. Radovan \& Kristl (2017) examined the acceptance and use of Learning Management Systems (LMS) among higher-education teachers and the relation between their use of such systems and their teaching approaches in the context of online learning, following the Community of Inquiry (CoI) framework using a sample of 326 teachers at University of Ljubljana. The study found that the crucial factor for LMS acceptance by university teachers is the immediate social influence at work, but the formation of the learning process largely depends on the characteristics of the LMS tools and the perceived usefulness of the application. In their own study, Raman, et al. (2014) examined the level of acceptance of Learning Management System (Moodle) among Postgraduate Students using Unified Theory of Acceptance and Use of Technology (UTAUT) from a sample of 65 postgraduate students. Findings of the study revealed that Performance Expectancy, Social Influence, and Facilitating Conditions have positive and significant influence towards Behavioral Intention. Alshehri et al., (2019) examined the implementation of UTAUT Model for understanding students' perceptions of Learning Management Systems in Saudi Arabia. Using Structural Equation Modelling (SEM), the study revealed that technical support is fundamental in determining the acceptance and use of e-learning systems. Liebenberg et al., (2018) determined the applicability of the UTAUT model to clarify the factors that are influencing students' intentions to make use of two digital technologies using a sample of 738 ICT students in South Africa. The study revealed that Performance Expectancy, Facilitating Condition and Effort Expectancy showed significant relationships with Behavioural Intention, Self-efficacy, and Attitude Towards using Technology.

\subsection{Learning Management Systems}

Learning management systems (LMSs) are applications used for the delivery of learning content and facilitation of learning process. These platforms are used mainly for administration and teaching within an educational institution. LMSs allow users electronic access and use of data entered into the system, for administrative purpose while also allowing course providers or tutors share electronic course materials to students who access and carry out a variety of assessments. Sife et al ( 2007) in 


\section{LICNAEDULATIIN}

02-04 JULY, 2021

Oxford, United Kingdom

Nicholas-Omoregbe (2017) further stated that the activities managed by the LMS vary from instructor-led classroom training to educational seminars to Web-based online training. In addition to managing the administrative functions of online learning, these systems are called Learning Content Management Systems, which help develop, reuse, locate, distribute, maintain and enhance learning content (LCMS). In particular, LMS could be used by both educational and corporate organizations with a significant emphasis on controlling the educational process rather than simply electronically distributing courses and training materials.

LMSs can be open source or commercial. Numerous other tools could be used in an educational setting, but most are designed for K-12 or corporate training environments. According to Claar (2014), examples include Moodle, Haiku, and Litmos. Several open source LMS are available, but may not have features needed in a university setting Prensky (2001) in Nicholas-Omoregbe (2017). Examples include aToutor, Canvas, Efront, Fedena, LAMS, Moodle and SWAD. Other examples are Blackboard, WebCT, eCollege, Desire2Learn, Angel. The most popularly used LMSs include: Moodle, WebCT and Blackboard, which are developed mostly using open source technology. According to Kulresthra(2013), the important features of any educational learning management system would include the following:-

1. Content management: Course material such as lecture notes prepared in soft copy may be included as part of the application package and uploaded to be used in classroom teaching.

2. Assessment and testing: All assignments shall be delivered and submitted online using the LMS, while quizzes/tests shall be instantly graded.

3. Curriculum Planning: LMS shall be used for designing of course plan and lecture schedule.

4. Reports generation: LMS provide easy to use and reliable reporting tools with options to customize student's reports.

5. Communication and collaboration: Most learning management systems provide chat, forum discussions as communication tools and wiki, blog, glossary e.t.c as collaborative tools.

6. Classroom and college announcements: Classroom and College news are visible as Announcements in LMSs.

\subsection{Distance Learning Centre, Ahmadu Bello University, Zaria.}

The Distance Learning Centre, Ahmadu Bello University (A.B.U) Zaria, opened up in the 2015/2016 academic session, with a single programme, the Masters in Business Administration (MBA), and an enrolment of over 2,000 students. The initial objective of commencing the Open and Distance Learning delivery in A.B.U Zaria, was to extend the reach of the Postgraduate School in the provision of quality and reputable postgraduate studies leading to the award of Ahmadu Bello 


\section{LNAEDULATIION}

02-04 JULY, 2021

Oxford, United Kingdom

University postgraduate degrees. In 2017, the Centre secured approval from National Universities' Commission, the country's accreditation and supervisory body for Tertiary Institutions, to run three undergraduate programmes, one post graduate diploma programme and Bachelor of Nursing Science programme. In addition, at the beginning of 2020, the Centre further applied to the NUC for license to start about ten undergraduate and Masters programmes, this will make a total of 16 programmes delivered by Distance Learning method.

The Distance Learning Centre, Ahmadu Bello University Zaria, uses innovative technologies in its Distance education delivery. Having started with one programme, the Masters in Business Administration, it uses technological innovations such as structured courseware, a Learning Management System, which is Moodle based, webinars for tutorials and addressing students, and a 24/7 user support using technology, to mention a few (Kabir, 2019). The DLC, A.B.U Zaria is indeed one of the very few Distance Learning Centres in Nigeria that uses a Learning Management System to provide a virtual classroom which is used for $80-90 \%$ interaction with the students.

\subsection{Theoretical Framework}

The theoretical framework for the study is anchored on Unified Theory of Acceptance and Use of Technology (UTAUT). The UTAUT is a model developed by Venkatesh, et al. (2003), synthesized from eight existing models of use of technology which include; Theory of Reasoned Action (TRA), Theory of Planned Behaviour (TPB), Technology Acceptance Model (TAM), a combination of Technology Acceptance Model (TAM) and Theory of Planned Behaviour (TPB) Model (C-TPBTAM), Diffusion of Innovation Theory (DOI), Motivational Model (MM), Model of PC Utilization (MPCU), and Social Cognition Theory (SCT) (Oshlyansky et al., 2007). Venkatesh, et al. (2003) formulated the UTAUT, by integrating the fragmented constructs in the eight models into a unified theoretical model and hypothesised that performance expectancy, effort expectancy, social influence and facilitating conditions can be significant in the determination of crucial moderators as; age, gender, experience and voluntariness of use.

The four major constructs, as follows determine technology acceptance and use in the UTAUT model and how they are related to similar variables in the eight models reported by Qeisi \& Abdallah (2013)

i. $\quad$ Performance Expectancy (PE): This means how much an individual agrees that utilizing the new technology will help him/her to accomplish gains in his job. The constructs in different models that relate to performance expectancy are perceived usefulness (TAM, and combined TAM-TPB), extrinsic motivation (MM), job-fit (MPCU), relative advantage (DOI), and outcome expectancy (SCT). This construct, in every individual model, was the most grounded indicator of intention and stayed critical at all purposes of estimation in both deliberate and required settings;

ii. Effort Expectancy (EE): is defined as the degree of ease of use of the technology. Perceived ease of use (TAM), and complexity (DOI and MPCU) are constructs in the other models which capture the same concept. The construct in each individual model was significant in both intentional and obligatory settings. 


\section{LICNAEDUCATIIN}

02-04 JULY, 2021

Oxford, United Kingdom

iii. Social Influence (SI): This describes how much an individual sees that people important to him accepts his use of the new technology. Similar constructs are represented in existing models: subjective norms (TRA, TAM2, TPB/DTPB, and combined TAM-TPB), social factors (MPCU), and image (DOI). The examination between models found that this construct acted also; it is unimportant in intentional settings and becomes critical when use is compulsory. Literature has shown that in obligatory settings, the impact is ascribed to consistence and has all the earmarks of being significant just in the beginning phases of individual experience and when rewards/discipline are relevant. Conversely, social impact in intentional settings works by affecting insights about the innovation (what is known as internalization and identification).

iv. Facilitating Conditions (FC): How much an individual accepts that a hierarchical and specialized foundation exists to help utilization of the technology. This definition captures three different constructs in existing models: combined TAM-TPB), facilitating conditions (MPCU), perceived behavioural control (TPB/DTPB) and compatibility (DOI). The comparison between models shows that the relationship between intention and this construct in each model is similar in both voluntary and mandatory settings. Literature has confirmed that when both performance expectancy and effort expectancy constructs are present, facilitating conditions will become insignificant; facilitating conditions are also directly related to usage (Al-Queisi \& Al-Abdallah, 2013; Venkatesh et al., 2003).

According to Venkatesh et al. (2003), the effect of these four constructs is influenced by four other variables:

i. Age: the degree to which the age of an individual will impact their use of a new system.

ii. Gender: the extent to which being a female or male makes it easy to use a new system.

iii. Experience: the degree of use over time with gaining experience in the use of a system.

iv. Voluntariness: the degree the system is used voluntarily.

Two of the constructs of UTAUT resemble TAM constructs: PE can be mapped to perceived usefulness (PU) whereas EE can be mapped to perceived ease of use (PEOU); while the remaining two constructs (SI and FC) are from TPB. Because of the comparability (in terms of constructs and relationships) of UTAUT with TAM and TPB, the current and future selection and dispersion studies may prefer utilization of UTAUT. This is especially more so since a large number of researchers have pointed to over-use of TAM.

Performance expectancy and effort expectancy are used to integrate variables such as perceived usefulness and ease of use. The model suggested that the effort expectancy construct could be quite significant in determining user acceptance of information technology. The model explains that individual differences greatly influence technology use. The UTAUT as shown in figure 2.1 was developed to explain users' behavioural intention to use an information system as well as increase usage behaviour (Alshehri, Drew, \& AlGhamdi, 2013).

Figure 2.1: Unified Theory of Acceptance and Use of Technology 
Despite the fact that the UTAUT model is generally new, its reasonableness, legitimacy and dependability in technology adoption studies in various settings have been demonstrated by various researchers (Anderson and Schwager, 2004; Lin, Chan, and Jin, 2004; Venkatesh et al., 2003). According to (Lin and Anol, 2008; Wang, Wu, and Wang, 2009), UTAUT presents the two advantages and limitations in its applications. UTAUT's advantages include: an all-encompassing methodology in clarifying the fundamental connections among numerous mental and social factors that may affect technology adoption; and the consistent validity and reliability of the data collected by UTAUT instruments.

For its limitations, even though the model has been widely accepted by different scholars, a major shortcoming is that, Attitude, which refers to an individuals' feelings (positive or negative) towards the use of the technologies, which is an important component of the TRA and the TAM, is not explicitly included in the UTAUT model (Thomas, Singh, \& Gaffar, 2013). In spite of this, the benefits obtained from this model have exceeded the shortcomings mentioned above (MayerSchönberger \& Lazer, 2007).

\subsection{Research Design}

\section{METHODOLOGY}


The study is quantitative in nature and employs an online survey for data collection. Online surveys provide researchers with various benefits, saving researchers time and expenses by overcoming geographic distance. Moreover, they assist in accessing unique subjects (Alharbi \& Drew, 2014).

\subsection{Population of the Study}

The population of the study is constituted by the entire E-tutors of Ahmadu Bello University, Distance Learning Center (ABUDLC). The ABUDLC has a total number of 237 E-tutors from various courses which include; Masters in Business Administration (MBA), Post Graduate Diploma in Education (PGDE), B Sc Nursing, B Sc Economics, B Sc Public Administration, and B Sc Business Administration as shown in table 3.1.

Table 3.1: Population of the Study

\begin{tabular}{|l|l|}
\hline MBA & 87 \\
\hline PGDE & 13 \\
\hline B SC Nursing & 55 \\
\hline B SC Economics & 26 \\
\hline B SC Public Administration & 32 \\
\hline B SC Business Administration & 24 \\
\hline Total & 237 \\
\hline
\end{tabular}

\section{Source: $A B U D L C$}

\subsection{Sampling and Sampling Technique}

Sampling can be defined as a process of selecting a portion of a population considered adequate to represent all the existing characteristics of the population for the purpose of generating the finding from the sample. According to Weyers (2011) a sample is a representative subset of the whole population. It is the process of selecting a subset of the population. To determine appropriate sample size, the study employed Yamani's formula specified as:

$$
n=\frac{N}{1+N e^{2}}
$$

Where $\mathrm{n}=$ Sample size, $\mathrm{N}=$ Total population, and $\mathrm{e}=$ Level of significance

Substituting $\mathrm{N}=237$ and $\mathrm{e}=0,05$ in equation 3.1, we get;

$$
n=\frac{237}{1+237(0.05)^{2}}=148.822 \approx 149
$$

Therefore, the appropriate sample size for the study is approximately 149 respondents. Also, the proportion of the sample size for each component of the population can be calculated as:

Sample proportion $=\frac{X}{N} \times n$

Where $\mathrm{X}=$ Sub-population, $\mathrm{N}=$ Total population, $\mathrm{n}=$ Sample size

The sample proportion is presented in table 3.2

Table 3.2: Sample Proportion

\begin{tabular}{|l|l|}
\hline MBA & 55 \\
\hline PGDE & 8 \\
\hline B SC Nursing & 35 \\
\hline B SC Economics & 16 \\
\hline
\end{tabular}




\begin{tabular}{|l|l|}
\hline B SC Public Administration & 20 \\
\hline B SC Business Administration & 15 \\
\hline Total & $\mathbf{1 4 9}$ \\
\hline
\end{tabular}

Source: Researcher's computation

Furthermore, the study employed purposive sampling technique to access the respondents. This is a type of sampling technique whereby the researcher selects respondents based on his own personal judgment, keeping in mind the purpose of the study. Purposive sampling techniques was used because it is less costly, more readily accessible, more convenient and select only those individuals that are relevant to research design.

\subsection{Instrument of Data Collection}

In order to collect data from the respondents, the study employed questionnaire technique of data collection. The questionnaire which includes both closed and open-ended questions was filled by the respondents. It was divided into two sections; section A contained demographic information of the respondents, while section B contained questions related to the relationship between Unified Theory of Acceptance and Use of Technology (UTAUT) and using Learning Management System.

\subsection{Reliability of the Instrument}

In order to measure the reliability of the instrument, Cronbach's Alpha measure was used. This is the most common measure of scale reliability (Field, 2009). Cronbach's Alpha measures the internal consistency between items to decide whether the different items in a questionnaire consistently reflect the construct that it is measuring (Field, 2009). Cronbach Alpha value exceeds 0.7 would be considered to have internal consistency reliability as used in many studies such as: Drost (2012) and Alharbi \& Drew (2014). The Cronbach Alpha can be calculated as:

$$
\alpha=\frac{N \bar{C}}{\bar{V}+(N-1) \bar{C}}
$$

Where $\mathrm{N}=$ number of items, $\bar{C}=$ average covariance between item-pairs, and $\bar{v}=$ average variance George and Mallery (2003) provide the following rules of thumb. Cronbatch's Alpha values:

$" \geq 0.9$ Excellent, $\geq 0.8$ Good, $\geq 0.7$ Acceptable, $\geq 0.6$ Questionable, $\geq 0.5$ Poor, and $\leq 0.5$ Unacceptable".

\subsection{Method of Data Analysis}

To examine the relationship between Unified Theory of Acceptance and Use of Technology (UTAUT) and using Learning Management System in Ahmadu Bello University Distance Learning Centre, the study employed multiple regression analysis specified as:

$$
L M S U=\alpha+\beta_{1} P E+\beta_{2} E E+\beta_{3} S I+\beta_{4} F C+\mu
$$

LMSU represents Learning Management System Use, PE represents Performance Expectancy, EE represents Effort Expectancy, SI represents Social Influence, FC represents Facilitating Conditions, $\alpha$ represents Constant or intercept, $\beta_{1}-\beta_{4}$ represents parameter estimate, $\mu$ represents error term.

\subsection{Response Rate}

\section{ANALYSIS AND DISCUSSION OF THE RESULT}




\section{SILNAEDUCATION}

02-04 JULY, 2021

Oxford, United Kingdom

In this section, the study presents the response rate of the respondents. A total number of 149 questionnaires were administered to the E-Tutors of Ahmadu Bello University Distance Learning Centre (ABUDLC). The result of the response rate presented in table 4.1 shows that out of 149 questionnaires administered, 110 representing $74 \%$ were returned and valid while 39 representing $26 \%$ were not returned.

Table 4.1: Response Rate

\begin{tabular}{|l|l|l|}
\hline & No. of Questionnaire & Percentage \\
\hline Returned & 110 & $74 \%$ \\
\hline Not return & 39 & $26 \%$ \\
\hline Total & 149 & 100 \\
\hline
\end{tabular}

Source: Researcher's computation

\subsection{Demographic Information of Respondents}

In this section, the study analyzed the demographic information of ABUDLC E-tutors. The result presented in table 4.2 shows that out of 110 E-tutors, 80 tutors representing $72.7 \%$ were males while 30 representing $27.3 \%$ were females. This implies that there are more male tutors than females in ABUDLC. The result also analyzed the age groups of E- tutors of ABUDLC as shown in table 4.2. It shows that out of 110 tutors, 70 representing $63.6 \%$ falls within the age group of $35-44$ years. This was followed by the age group 25-34 years with 30 tutors representing $27.3 \%$. The age group that has the lowest frequency was 45 years and above with only 10 tutors representing $9.1 \%$. This implies that most of the E-tutors in ABUDLC are youth who are within their productive age. In terms of Etutors' qualification, the result presented in table 4.2 shows that out of 110, 75 E-tutors representing 68.2\% were MSc./M.A holders while 35 E-tutors representing 31.8\% were Ph.D. holders. This implies that there are more MSc./M.A holder than Ph.D. holders among the ABUDLC E-tutors.

Furthermore, the result of the demographic information of respondents presented in table 4.2 shows the various ranks of E-tutors in ABUDLC. Out of 110 respondents, the E-tutors with the highest frequency were Lecturer I with 40 tutors, representing 36.4\% followed by Assistant Lecturer with 26 tutors, representing 22.7\%, then Lecturer II with 15 tutors, representing 13.6\%. However, the Etutors with the lowest frequency were Senior Lecturers, Professors, and others with 10 tutors each representing 9.1\%. This implies that most of the E-tutors in ABUDLC were junior lecturers while there were few Senior Lecturers and Professors. With respect to E-tutors faculty, the result shows that out of 110 E-tutors, 45 representing $40.9 \%$ were from Faculty of Administration, followed by 30 representing $27.3 \%$ who were from faculty of Social Sciences. Also, the result shows that 20 E-tutors representing 18.2\% were from Faculty of Medicine while 15 E-tutors representing 13.6\% were from other faculties. The result implies that most of the E-tutors of ABUDLC were from Faculty of Administration and Faculty of Social Science.

Finally, the result presented in table 4.2 shows the number of E-tutors taking a particular course at ABUDLC. The result shows that out of 110 E-tutors, 45 representing 40.9 were taking MBA, followed by 25 E-tutors representing $22.7 \%$ who were taking each of Nursing science and Public Administration. Another 10 E-tutors representing 9.1\% were taking PGDE while the course with the least number of E-tutors is Economics with 5 E-tutors representing 4.5\%. The result implies that about $50 \%$ of E-tutors in ABUDLC are taking Public Administration.

\section{Table 4.2: Demographic Information of Respondents}




\begin{tabular}{|c|c|c|}
\hline Tutor's Gender & Frequency & Percentage \\
\hline Male & 80 & 72.7 \\
\hline Female & 30 & 27.3 \\
\hline Total & 110 & 100.0 \\
\hline Tutor's Age Group & Frequency & Percentage \\
\hline $25-34$ years & 30 & 27.3 \\
\hline $35-44$ years & 70 & 63.6 \\
\hline 45 years and above & 10 & 9.1 \\
\hline Total & 110 & 100.0 \\
\hline Tutor's Qualification & Frequency & Percentage \\
\hline M SC/MA & 75 & 68.2 \\
\hline P HD & 35 & 31.8 \\
\hline Total & 110 & 100.0 \\
\hline Tutor's Rank & Frequency & Percentage \\
\hline Assistant Lecturer & 25 & 22.7 \\
\hline Lecturer II & 15 & 13.6 \\
\hline Lecturer I & 40 & 36.4 \\
\hline Senior Lecturer & 10 & 9.1 \\
\hline Professor & 10 & 9.1 \\
\hline Others & 10 & 9.1 \\
\hline Tutor's Faculty & Frequency & Percentage \\
\hline Faculty of Administration & 45 & 40.9 \\
\hline Faculty of Social Science & 30 & 27.3 \\
\hline Faculty of Medicine & 20 & 18.2 \\
\hline Others & 15 & 13.6 \\
\hline Total & 110 & 100.0 \\
\hline Tutor's Course in ABUDLC & Frequency & Percentage \\
\hline MBA & 45 & 40.9 \\
\hline PGDE & 10 & 9.1 \\
\hline Nursing Science & 25 & 22.7 \\
\hline B SC Economics & 5 & 4.5 \\
\hline B SC Public Administration & 25 & 22.7 \\
\hline Total & 110 & 100.0 \\
\hline
\end{tabular}

Source: Field Survey, 2020

\subsection{Reliability of Scale}

In order to measure the reliability of the scales, Cronbatch's Alpha measure was used because it is the most commonly used measure of scale reliability (Field, 2009). Cronbatch's Alpha measures the internal consistency between items to decide whether the different items in a questionnaire consistently reflect the construct that it is measuring (Field, 2009). Constructs are considered to have internal consistency reliability when the Cronbach's Alpha value exceeds 0.7 (Alharbi \& Drew, 2014). The Cronbach's Alphas of the five constructs of the study are shown in table 4.3. The Cronbatch's Alpha values of the independent variables such as; performance expectancy, effort 
expectancy, social influence, and facilitating condition ranges from 0.718 to 0.874 which implies that all the values are above the threshold of 0.7, meaning that the reliability is confirmed (Nunnally, 1978). However, the Cronbatch's Alpha value of 0.015 for LMS Use is unacceptable.

Table 4.3: Reliability of Scale

\begin{tabular}{|l|c|c|}
\hline Construct & Cronbatch's Alpha (a) & No of Items \\
\hline Performance Expectancy & 0.874 & 3 \\
\hline Effort Expectancy & 0.814 & 3 \\
\hline Social Influence & 0.725 & 2 \\
\hline Facilitating Condition & 0.718 & 2 \\
\hline LMS Use & 0.015 & 2 \\
\hline
\end{tabular}

Source: Researcher's Computation

\subsection{Model Summary}

To check if the model fits the data, we look at the model summary presented in table 4.5. The result shows that the $\mathrm{R}^{2}$ value of 0.339 means that the independent variables accounted for about $33.9 \%$ of the variation in the dependent variable while the remaining $66.1 \%$ was captured by the residuals. Also, to check whether the model has serial or autocorrelation, we look at Durbin-Watson statistics presented in table 4.5. The result shows that the Durbin-Watson statistics value of 1.69 which is close to 2. This implies that the model has no problem of serial or autocorrelation.

Table 4.4: Model Summary

\begin{tabular}{|l|l|l|l|l|l|}
\hline Model & $\mathrm{R}$ & R Square & Adjusted R Square & $\begin{array}{l}\text { Std. Error of the } \\
\text { Estimate }\end{array}$ & Durbin-Watson \\
\hline & 0.582 & 0.339 & 0.313 & 0.473 & 1.690 \\
\hline
\end{tabular}

Source: Field Survey, 2020

\subsection{Overall Model Fitness}

To examine the overall fitness of the models, Analysis of Variance was used. The result in table 4.6 shows that the independent variables are jointly significant at $1 \%$ level of significance, as the probability values of F-statistic is less than 0.01 . Therefore, we conclude that the model fits the data. 


\section{SILNAEDUCATION}

02-04 JULY, 2021

Oxford, United Kingdom

\begin{tabular}{|l|l|l|l|l|l|}
\hline Model & Sum of Squares & Df & Mean Square & F & P.Value \\
\hline Regression & 12.006 & 4 & 3.001 & 13.440 & 0.000 \\
\hline Residual & 23.449 & 105 & 0.223 & & \\
\hline Total & 35.455 & 109 & & & \\
\hline
\end{tabular}

Source: Field Survey, 2020

Having satisfied with the model fitness, the next thing is to analyze coefficients of the regression model. The result presented in table 4.7 shows that there is positive but insignificant relationship between performance expectancy and LMS use at 5\% level of significance in ABUDLC. A unit increase in performance expectancy causes LMS use to increase by about 0.03 . This finding is consistent with Liebenberg et al., (2018) who found that Performance Expectancy showed high practically significant relationships with Behavioural Intention. However, the result shows that there is a negative and significant relationship between effort expectancy and LMS use at $1 \%$ level of significance in ABUDLC. A unit increase in effort expectancy causes LMS use to decrease by about 0.4. This finding is not consistent with Liebenberg et al., (2018) who found that Effort Expectancy showed high practically significant relationships with Behavioural Intention, Self-efficacy, and Attitude Towards using Technology. The result further shows that there is a negative and significant relationship between social influence and LMS use at least at $10 \%$ level of significance in ABUDLC. A unit increase in social influence causes LMS use to decrease by about 0.08 . This finding is not consistent with Raman, et al. (2014) who found that Social Influence have positive and significant influence towards Behavioral Intention. However, the result shows that there is a positive and significant relationship between facilitating condition and LMS use at $1 \%$ level of significance. A unit increase in facilitating condition causes LMS use to increase by about 0.38 . This finding is consistent with Liebenberg et al., (2018) who found that Facilitating Condition showed high practically significant relationships with Behavioural Intention, Self-efficacy, and Attitude Towards using Technology.

Table 4.6: Coefficients

\begin{tabular}{|l|l|l|l|l|l|}
\hline Model & \multicolumn{2}{|l|}{$\begin{array}{l}\text { Unstandardized } \\
\text { Coefficients }\end{array}$} & $\begin{array}{l}\text { Standardized } \\
\text { Coefficients }\end{array}$ & & \\
\hline Independent Variable & $\mathbf{B}$ & $\begin{array}{l}\text { Std. } \\
\text { Error }\end{array}$ & Beta & T & P.Value \\
\hline Constant & 2.552 & 0.198 & & 12.903 & $0.000^{*}$ \\
\hline Performance expectancy & 0.036 & 0.099 & 0.037 & 0.367 & 0.714 \\
\hline Effort expectancy & -0.434 & 0.112 & -0.380 & -3.871 & $0.000^{*}$ \\
\hline
\end{tabular}




\section{SILNAEDUCATION}

02-04 JULY, 2021

Oxford, United Kingdom

\begin{tabular}{|l|l|l|l|l|l|}
\hline Social influence & -0.083 & 0.043 & -0.175 & -1.939 & $0.055^{* * *}$ \\
\hline Facilitating condition & 0.384 & 0.077 & 0.481 & 5.024 & $0.000^{*}$ \\
\hline
\end{tabular}

Source: Source: Field Survey, 2020

$*$,**, and *** represents 1\%, 5\%, and $10 \%$ level of significance respectively Dependent Variable: Learning Management System Use.

\section{CONCLUSION AND RECOMMENDATION}

The study examined the application of Unified Theory of Acceptance and Use of Technology to Learning Management System use in Ahmadu Bello University Distance Learning Centre (ABUDLC). The study concludes that the model adequately explained and predicts behavioral intention to adopt E-learning in ABUDLC. Performance expectancy and facilitating conditions indicates positive relationship with behavioral intention to adopt the use of LMS while effort expectancy and social influence indicate negative relationship with behavioral intention to adopt the use of LMS in ABUDLC. Notwithstanding, the UTAUT model remains an important determinant of behavioral intention to use LMS in ABUDLC.

\subsection{Results of Findings}

1. There is a positive but insignificant relationship between performance expectancy and LMS use at 5\% level of significance in ABUDLC. A unit increase in performance expectancy causes LMS use to increase by about 0.03 . This means that e-tutors with high performance expectancy (who believe that using LMSs will be beneficial to them in their tutoring) have a tendency to accept LMSs rather than e-tutors with lower performance expectancies.

2. There is a negative and significant relationship between effort expectancy and LMS use at $1 \%$ level of significance in ABUDLC. A unit increase in effort expectancy causes LMS use to decrease by about 0.4 . This implies that there is evidence of positive relationship between effort expectancy and LMS use in ABUDLC which means e-tutors in ABUDLC are not proactive in LMS use.

3. There is a negative and significant relationship between social influence and LMS use at least at $10 \%$ level of significance in ABUDLC. A unit increase in social influence causes LMS use to decrease by about 0.08 . This implies that there is no evidence of positive relationship between social influence on LMS use in ABUDLC which means that e-tutors in ABUDLC are not influenced by the behavior of other towards LMS use.

4. There is a positive and significant relationship between facilitating condition and LMS use at $1 \%$ level of significance. A unit increase in facilitating condition causes LMS use to increase by about 0.38. This implies that e-tutors in ABUDLC are greatly influenced by facilitating condition, particularly training/workshop on LMS use.

\subsection{Implications and Recommendations of Study}

In order to improve on the behavioral intention to use and adopt Learning Management use in ABUDLC, the study makes the following recommendations in line with the above findings:

1. Although there is a positive relationship between performance expectancy and LMS use in ABUDLC, the relationship is insignificant. Therefore, the E-tutors in ABUDLC should improve on performance expectancy towards their behavioural intention to use LMS. 


\section{LICNAEDULATIIN}

02-04 JULY, 2021

Oxford, United Kingdom

2. The negative and significant relationship between effort expectancy and LMS use in ABUDLC indicates that the E-tutors should put more effort in their behavioural intention to use LMS.

3. The negative and significant relationship between social influence and LMS use in ABUDLC indicates that to improve on their behavioural intention to use LMS, the E-tutors should be consulting and learning from their colleagues in ABUDL or somewhere else.

4. The positive and significant relationship between facilitating condition and LMS use is an indication that ABUDLC is doing well by providing E-tutors with the necessary facilities. Notwithstanding, the management of ABUDLC should provide E-tutors with more facilitating condition particularly, technical support and regular training on LMS use. Indeed, the quality of delivery offered by these new learning systems needs to include user-friendliness, meeting most of the requirements of E-Tutors, and provision of quality technical support among others.

\section{REFERENCE}

Al Busaidi (2010). Communications of the IBIMA. Vol. 2010 (2010), Article ID 862128, 10 pages http://www.ibimapublishing.com/journals/CIBIMA/cibima.html

Alharbi, S., \& Drew, S. (2014). Using the Technology Acceptance Model in Understanding Academics' Behavioural Intention to Use Learning Management Systems. International Journal of Advanced Computer Science and Applications, 5(1), 143-155. https://doi.org/10.14569/ijacsa.050120

Alshehri, A., Rutter, M. J., \& Smith, S. (2019). An implementation of the UTAUT model for understanding students' perceptions of Learning Management Systems: A Study within Tertiary Institutions in Saudi Arabia. International Journal of Distance Education Technologies, 17(3), 1-24. https://doi.org/10.4018/IJDET.2019070101

Alrawashdeh, T. A., Muhairat, M.I. \& Alqatawnah, S. M. (2012). Factors affecting acceptance of web-based training system: using extended UTAUT and structural equation modeling. International Journal of Communication.

Anderson, J. E., \& Schwager, P. H. (2004). SME adoption of wireless LAN technology: Applying the UTAUT model. January 2004.

Anene, J. N., Imam,H. and Odumuh. T. (2014). Problem and Prospect E-learning in Nigerian Universities. International Journal of Technology and Inclusive Education (IJTIE), Volume 3, Issue 2, December 2014.

Asiri, M. J., Mahmud, R., Bakar, A., and Ayub, F. M. (2012). "Role of Attitude in Utilization of Jusur LMS in Saudi Arabian Universities," Procedia - Social and Behavioral Sciences, vol. 64, pp. 525-534.

Claar, C. (2014). Student Acceptance of Learning Management Systems: A Study on Demographics. Issues in Information Systems, 15 (1), 409-417.

Davis, F. D. (1993). User acceptance of information technology: system characteristics, user perceptions and behavioral impacts. Int. J. Man-Machine Studies, 38 (3): 475-487. 


\section{STENEDUCATION}

02-04 JULY, 2021

Oxford, United Kingdom

Drost, W. (2012). The Influence Of Entrepreneurial Intent, (Non) Linear Thinking, Mindfulness And Neuroticism \& Conscientiousness On Procrastination. University of Twente.

Fidani, A., \& Idrizi, F. (2012). Investigating Students 'Acceptance of a Learning Management System in University Education: A Structural Equation Modeling Approach. ICT Innovations 2012, 311-320.

Field, A. (2009). Discovering Statistics Using SPSS. London: SAGE Publications Ltd.

Fishbein and Ajzen, (1975). Theory of Reasoned Action. Retrieved from https://www.researchgate.net/figure/Theory-of-reasoned-action-Fishbein-and-Ajzen1975-1980_fig1_268289434 on 12 $2^{\text {th }}$ June 2020.

George, D., \& Mallery, P. (2003). SPSS for Windows step by step: A simple guide and reference. 11.0 update (4th ed.). Boston: Allyn \& Bacon.

Johnson, L., Adams Becker, S., Cummins, M., Estrada,V., Freeman, A., and Ludgate H. (2013). New Media Consortium Horizon Report: Higher Education Edition. Austin, TX: The New Media Consortium.

Kabir, F. S. (2016). Awareness, Perception and Utilization of Mobile Devices in Tertiary Distance Education Institutions in Nigeria. Unpublished PhD. Dissertation submitted to Ahmadu Bello University, Zaria. November 2016.

Kabir, F.S and Tukur, A.K (2017). ICTs and Educational Development: The Utilization of Mobile Phones in Distance Education in Nigeria. Turkish Online Journal of Distance Education. Anadolu University, Turkey. Vol. 18 no.1 (January 2017).

Kabir, F.S. (2018). Correlation of Awareness and Usage of Mobile Devices amongst Facilitators and Students of Distance Education in Nigeria. ATBU Journal of Science, Technology and Education (JOSTE). Vol. 6 (3), September, 2018. Abubakar Tafawa Balewa University, Bauchi.

Kabir, F.S. (2019). Technology-Enabled Distance Education: A Case for an Open and Distance Education Regulatory Agency in Nigeria. Journal of Science, Technical, Mathematics and Education, Federal University of Technology Minna, 15(3), September 2019.

Kulshrestha, T., \& Kant, A. R. (2013). Benefits of Learning Management System (LMS) in Indian Education. International Journal of Computer Science \& Engineering Technology (IJCSET). 7 (2).

Liebenberg, J., Benade, T., \& Ellis, S. (2018). Acceptance of ICT: Applicability of the Unified Theory of Acceptance and Use of Technology (UTAUT) to South African Students. The African Journal of Information Systems, 10(3), 1.

Lin, P., Lu, H.,\& Liu, S. (2013). Towards an education behavioral intention model for elearning 


\section{SINAEDUCATION}

02-04 JULY, 2021

Oxford, United Kingdom

systems: An extension of UTAUT. Journal of Theoretical and Applied Information Technology.47 (3).

Lin, C. and Anol, B. (2008). Learning online social support: An investigation of network information technology based on UTAUT. CyberPsychology \& Behaviour Vol. 11 (3). https://doi.org/10.1089/cpb.2007.0057

Lwoga, E.,\&Komba (2014). Understanding university students' behavioural continued intentions to use e-learning in Tanzania. Proceedings and Report of the 7th UbuntuNet Alliance Annual Conference, 167-188.

Maina and Nzuki Maina, M. K. \&Nzuki, D .M. (2015). Adoption Determinants of E-learning Management System in Institutions of Higher Learning in Kenya: A Case of Selected Universities in Nairobi Metropolitan. International Journal of Business and Social Science, 6 (2).

Mayer-Schoenberger, V. and Lazer, D. (2007). Governance and information technology: From electronic government to information government. Retrieved on $12^{\text {th }}$ June 2020 from https://www.belfercenter.org/publication/governance-and-information-technology electronic-government-information-government

Ngampornchai, A., \& Adams, J. (2016). Students' acceptance and readiness for E-learning in Northeastern Thailand. International Journal of Educational Technology in Higher Education, 13(1). https://doi.org/10.1186/s41239-016-0034-x

Nunnally, J.C. (1978). Psychometric Theory (2nd edition). New York: McGraw-Hill

Nicholas-Omoregbe, O.S., Azeta, A.A., Chiazor, I.A. and Omoregbe N. (2017). Predicting the Adoption of E-Learning Management System: A Case Of Selected Private Universities in Nigeria. Turkish Online Journal of Distance Education. Vol. 18, no. 2, Article 9.

Oshlyansky, L., Park, S., Cairns, P., Thimbleby, H., \& Park, S. (2007). Validating the Unified Theory of Acceptance and Use of Technology ( UTAUT ) tool cross-culturally. January. https://doi.org/10.1145/1531407.1531429

Prensky M. (2001). Digital Natives, Digital Immigrants. On the Horizon. Vol 9, issue 5:1-6. http://www.scribd.com/doc/9799/Prensky-Digital-Natives-Digital-Immigrants-Part1 (accessed January 28, 2019). Archived at http://www.webcitation.org/5eBDYI5Uw

Qeisi, K. Al, \& Al-abdallah, G. (2013). Internet banking adoption in Jordan : A behavioral approach. International Journal of Marketing Studies, 5(6), 84-108. https://doi.org/10.5539/ijms.v5n6p84

Radovan, M., \& Kristl, N. (2017). Acceptance of technology and its impact on teacher's activities in virtual classroom: Integrating UTAUT and CoI into a combined model. Turkish Online Journal of Educational Technology, 16(3), 11-22.

Raman, A., Don, Y., Khalid, R., \& Rizuan, M. (2014). Usage of Learning Management System 


\section{LCNAEDULATIION}

02-04 JULY, 2021

Oxford, United Kingdom

(Moodle) Among Postgraduate Students: UTAUT model. Asian Social Science, 10(14), 186192. https://doi.org/10.5539/ass.v10n14p186

Shittu A. T, Gambari A. I., and Sule, A. O (2013). Students' Attitude and Behavioural Intention on Adoption of Internet for Learning among Al-Hikmah University Students in Nigeria: A Test of Technology Acceptance Model. Malaysian Journal of Distance Education 15(2), 89-107 (2013)

Sife A. S., Lwoga, S.T., and Sanga, C. (2007). New technologies for teaching and learning: Challenges for higher learning institutions in developing countries. International Journal of Education and Development Using ICT. 3 (2).

Sikhanyiso, N. (2013). Community Development Projects and Food Security: The Case of Zanyokwe Irrigation Project Eastern Cape Province, South Africa.

Thomas, T. D., Singh, L., \& Gaffar, K. (2014). Measurement invariance of the UTAUT constructs in the Caribbean. International Journal of Education and Development Using Information and Communication Technology (IJEDICT), 10(4), 102-127.

Venkatesh, V., Morris, M., Davis, G., \& Davis, F. (2003). User Acceptance of Information Technology: Toward a Unified View. MIS Quatlerly, 27 (3): 425-478. In Nicholas-Omoregbe, O.S., Azeta, A.A., Chiazor, I.A. and Omoregbe N. (2017). Predicting the Adoption of ELearning Management System: A Case Of Selected Private Universities in Nigeria.

Wang, H. and Yang, H. (2005) The Role of Personality Traits in UTAUT Model under Online Stocking. Contemporary Management Research, 1(1) 69-82.

Wang, Y., Wu, M., \& Wang, H. (2009). Investigating the Determinants of Age and Gender Differences in the Acceptance of Mobile Learning. British Journal of Educational Technology, 40(1), 92-118.

Weyers, M. L. (2011). The theory and pracice of community work: A Southern African perspective. 